\title{
CHRONIC PAIN SYNDROMES AND THEIR TREATMENT III. THE PIRIFORMIS SYNDROME
}

\author{
Gordon M. WYaNT
}

LOW BACK PAIN with or without sciatica is a common condition seen in pain clinics. While in the majority of cases the pain is due to such classic conditions as degenerative disc disease, spondylitis, entrapment in the lateral recess, or similar causes, there are cases which are due to none of these and which therefore remain undiagnosed and unrelieved by any of the treatment modalities commonly employed. Yeoman in $1928^{\prime}$ first mentioned the piriformis muscle in connection with his thesis that some cases of sciatica are due to arthritic changes in the sacroiliac joint, but he failed to establish a direct relationship between sciatica and the piriformis muscle itself. It remained for Pace and $\mathrm{Nagle}^{2}$ to show that in some instances a back disability may be due to the existence of a trigger area in the piriformis muscle.

Trigger points in muscles are a common cause of musculo-skeletal pain and have been well described in the past. ${ }^{3}$ They are of particular clinical significance since they may produce symptoms at a distance and in locations which cannot always be explained by known anatomical relationships. These very distinct points of focal hyperirritability have been carefully examined, and their existence as a definite lesion has been established. ${ }^{4.5}$ The subject has been discussed in greater detail in an earlier paper by the author. 6

While most trigger points are in superficial skeletal muscles and can be easily looked for and identified, the piriformis is well hidden and it is probably for that reason that the existence of the syndrome has largely escaped notice.

\section{ANATOMY (Figure 1)}

The piriformis muscle originates with three digitations from the front of the sacrum, the gluteal surface of the ilium, and the anterior capsule of the sacro-iliac joint. Its origin thus is within the pelvis which it leaves through the greater sciatic

Gordon M. Wyant, C.D., M.D., F.F.A.R.C.S. F.R.C.P.(C). Pain Management Service, Department of Anaesthesia, University Hospital, Saskatoon and Plains Health Centre, Regina, University of Saskatchewan.

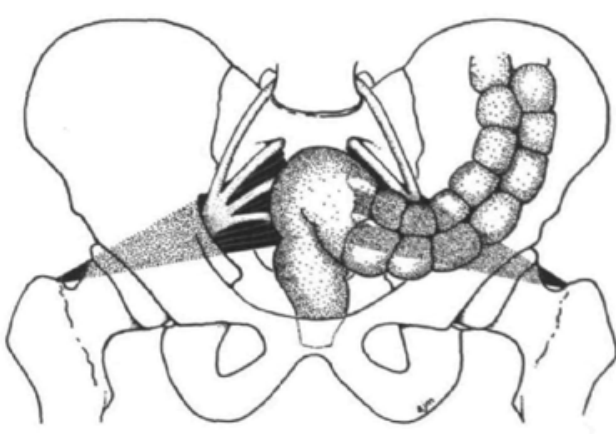

Figure 1 The piriformis muscle and its relationship to the sciatic nerve.

foramen to find insertion at the upper border of the greater trochanter by means of a rounded tendon. Its most significant relations for our purposes are the sciatic nerve which leaves the pelvis at the lower border of the piriformis, the nerve roots which exit through the sacral foramina, and the sacro-iliac joint. The muscle itself is innervated by branches from LS, S1 and S2, a fact which also bears some relation to the clinical picture which arises from hyperiritability of the muscle. Functionally the piriformis is primarily an external rotator of the hip joint when the thigh is extended at the hip joint and an abductor of the flexed thigh.

\section{Clinical Picture and Diagnosis}

As has been stated, patients may present with a variety of complaints referable to the lower spine. hip, pelvis or sciatic nerve. A history of trauma is often difficult to elicit since in many instances this has been minimal and has likely escaped the patient's attention. Since the symptomatology is non-specific, every patient presenting with pain in these areas should be examined for piriformis syndrome, unless there is overwhelming evidence of well-defined pathology elsewhere. It is interesting that despite the severity of symptoms, the usual clinical findings are often entirely absent and that there is good movement in the lum305

Canad. Anaesth. Soc. J., vol. 26, no. 4, July 1979 
examination might be a limitation of straight legraising. Neurological deficit referable to the sciatic nerve is invariably absent, but tenderness over the sciatic notch can almost always be elicited and should therefore be looked for in all cases of obscure pain. More specific, however, are tests based upon the function of the muscle, such as passive internal rotation of the thigh with the patient in the recumbent position or, better still, resisted abduction of the knees with the patient sitting and facing the examiner, as described by Pace and Nagle. ${ }^{2}$ The diagnosis is confirmed by palpation of the muscle itself on rectal or vaginal examination, when pressure on the muscle will reproduce the pain.

\section{Case Reports}

Patient 1: A.N. (S-181), a 31-year-old married lady has had low backache for the last five years. In the beginning she experienced the pain in the lumbar region only occasionally. She has no recollection of trauma preceding the onset of the pain. She improved with rest and a relaxant of unknown identity. After one year of occasional backache she consulted a chiropractor who manipulated her back and leg without success. Two years before she first attended our Pain Management Clinic the backache increased spontaneously, both in intensity and duration. and, after seeing the chiropractor again, she consulted an orthopaedic surgeon. He put her on further exercises and ultrasound, and it was at that time that she experienced the first twinges of pain in both legs, more on the right than on the left. She was given an orthopaedic belt. Within the next six months the pain in the right leg became constant. She was admitted to hospital and put into traction. After this the pain disappeared for a short time, but eventually returned and some ten months before she was seen here a myelogram was attempted, but the subarachnoid space could not be entered. Two months thereafter she had an exploratory laminectomy at two or three levels but no abnormality was found. Immediately after the operation the leg hurt much more than it had before, but with physiotherapy it improved somewhat over the next two or three months and then the pain became constant in intensity. Other treatment has consisted of cortisone injections "into her back" and of acupuncture, neither of which was successful. At this point the acupuncturist did a rectal examination, being the first physician to do so, and on finding tenderness at the right piriformis muscle, referred her to our Pain Management Clinic.

On examination the only abnormalities were a 30-degree limitation of straight leg raising on the right side, inability to bring the right heel above the left knee, pain deep in the right buttock on passive adduction of the right thigh and local tenderness over the right piriformis muscle. The muscle was injected and within a few minutes she had marked relief of symptoms. was able to cross her legs without discomfort and to bring the right heel up to the left midthigh. Her future course was uneventful. She attended another four times for reinjection to correct minor residual discomfort, but the pain never again reached its original intensity.

Patient 2: V.E. (R-151). This 58-year-old housewife sustained an injury seven months before she was seen in the clinic. Her leg had slipped behind her while she was bending down. At that time she felt something "snap" in her back and had had a low backache ever since. Immobilization in hospital, physiotherapy and a course of cyclobenzaprine had failed to give her relief. The only positive finding on physical examination was marked muscle spasm of the lumbar paraspinous muscles on both sides, and tenderness over the right sacro-iliac joint. Straight leg-raising was limited to 45 degrees on the left and 35 degrees on the right side. Both the active and passive test for piriformis syndrome were positive on the right side and, on pelvic examination, there was distinct tenderness over the right piriformis muscle. This was injected with $8 \mathrm{ml}$ of bupivacaine 0.25 per cent to which triamcinolone $80 \mathrm{mg}$ had been added and there was almost immediate relief of pain which was still 90 per cent relieved when she was seen one week later. At that time all tests for piriformis syndrome were negative.

\section{Discussion}

Low backache is a common ailment; the piriformis syndrome is not. Indeed, in Pace and Nagle*s series of 750 cases from a specialized back clinic, only 45 instances were recorded, an incidence of six per cent. Being relatively uncommon, it is often ignored as a factor in the differential diagnosis of low backache. The result is that treatment is unsuccessful, or worse, that patients are submitted to unnecessary and useless operations. We have made the test for piriformis involvement a routine part of the physical examination of all patients presenting 
with low backache, bearing in mind that the syndrome is six times more common in women than in men.

Since almost all superficial muscles have been shown to be potential sites of trigger points, ${ }^{3}$ it is reasonable to assume that the same might apply also to deep-seated skeletal muscles. Because of their hidden location, the symptomatology of only two has been clearly defined. The piriformis muscle is one of these, the other is the quadratus lumborum, another occasional source of low backache. It also yields to injection of local anaesthetic. In contrast to the piriformis, the diagnosis in that case is made by passive lateral flexion of the lumbar spine to the opposite side.

When injecting the piriformis muscle, the solution should be deposited deep within the fleshy substance of the muscle, that is, closer to the sacrum than to the greater trochanter. This portion of the muscle can be reached in a variety of ways. The one most universally available is through the sacral notch, the semilunar bony outline of which is easily palpable. With the patient in the lateral decubitus position with the affected side uppermost, and with the legs flexed at the knee and hip, the piriformis muscle is palpated by the rectal or vaginal route. The sacro-spinous ligament is easily felt as a tight band stretching from the sacrum to the ischial spine and constitutes a useful landmark. By exerting pressure upon the muscle, it should be possible to reproduce the pain. The needle is then inserted perpendicular to the skin to make contact with the rim of the notch, and is then realigned to slide tangentially past the bone into the substance of the muscle (Figure 2-b). The anaesthetic is injected when the needle can be felt under the palpating finger. If the original pain is reproduced it confirms the proper placement of the needle. Because of the proximity of the muscle to the sciatic nerve, Pace and Nagle suggest that a test dose of local anaesthetic be injected first and that some time be allowed to elapse. If anaesthesia in the distribution of the sciatic nerve does not develop, the local anaesthetic containing steroid can then be deposited. We follow this routine, although it is unlikely that the sciatic nerve could be contacted by the needle without paraesthesia being elicited. In the female we prefer to palpate the piriformis vaginally, since it is easier to reach by that route than via the rectum. In that case a spinal needle may be introduced from the perineum medial to the ischial tuberosity and advanced paravaginally into the muscte (Figure 2-a). Lastly the piriformis can be reached from

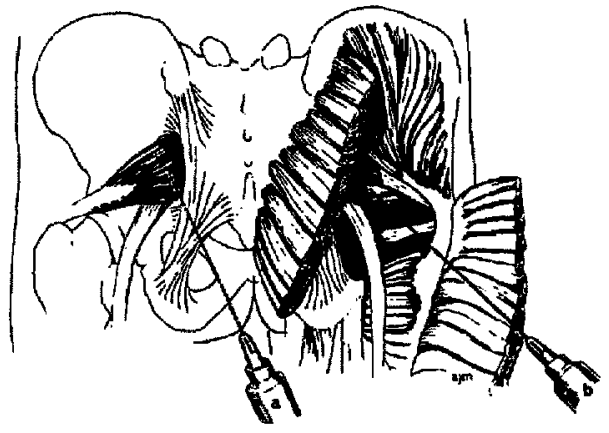

FIGURE 2 The paravaginal (a) and lateral approach through the sciatic notch (b) to the piriformis muscie. In the paravaginal approach the needie enters the muscle belly from the front, while by the lateral route the ncedle enters the muscle from its posterior surface.

the lateral fornix of the vagina, similar to the approach for para-cervical block. Whatever the approach, a well-placed injection will result in immediate and complete pain relief. We use a total volume of $8 \mathrm{ml}$ of lidocaine 0.5 per cent with triamcinolone $80 \mathrm{mg}$.

\section{SUMMARY}

The piriformis is a deep-seated muscle, most of its muscular portion being part of the dorsal wall of the pelvis. The lateral portion and its insertion is extra-pelvic and lies deep to the glutei. Like more superficially located and therefore more easily accessible skeletal muscles, the piriformis too can be the seat of trigger points, giving rise to symptoms indistinguishable from those of other causes of low backache, unless a deliberate search is made for the signs specific to the piriformis syndrome. Having made a presumptive diagnosis, confirmation is gained by palpating the muscle itself via rectum or vagina and reproducing the pain by digital pressure. If this test also is positive, the muscle is injected, the approach being either through the sciatic notch, from the perineum, or through the vagina. Immediate relief of pain is experienced after the solution of local anaesthetic and steroid has been deposited deep within the fleshy portion of the muscle.

\section{RÉSUMÉ}

Le syndrome du muscle pyramidal du bassin décrit la douleur originant des zones gachettes de ce muscle profondément situé et difficilement accessible à l'examen. L'importance de syndrome 
est due au fait qu'il imite la lombalgie qui est très fréquente et dont les causes sont multiples. Heureusement ses manifestations sont précises et il peut être diagnostiqué par des manceuvres spécifiques lorsqu'on examine un malade pour une lombalgie. De plus ce syndrome se traite de la mème façon que les zones gachettes de tout autre muscle squelettique par l'injection d'anesthésiques locaux. Le muscle est accessible par la grande échancrure sciatique, à travers le périnée ou par le vagin. La douleur disparait très rapidement après une injection dans la partie charnue du muscle pyramidal situé en avant du sacrum.

\section{REFERENCES}

1. YeOMAN, W. The relations of arthritis of the sacro-iliac joint to sciatica. Lancet 2: 1119-1122 (1928).

2. PACE, J.B. \& Nagle, D. Piriform syndrome. West J. Med. 124: 435-439 (1976).

3. Travell, J. \& RinzleR, S.H. The myofascial genesis of pain. Postgrad. Med, 11: 425-532 (1952).

4. Brendstrup, P., Jespersen, K. \& AsboeHANSEN, G. Morphological and chemical connective tissue changes in fibrostic muscles. Ann. Rheum. Dis., I6: 438-440 (1957).

5. AWAD, E.A. Interstitial myofibrositis: hypothesis of the mechanism. Arch. Phys. Med. and Rehab., 54: 449-453 (1973).

6. WYant, G.M. Chronic pain syndromes and their treatment. II. Trigger points. Can, Anaesth. Soc. J., 26: 216-219 (1979). 